\title{
Awareness and care seeking pattern for symptoms associated with endometrial carcinoma among postmenopausal women in the district of Colombo: a cross-sectional study
}

\author{
Withanage Iresha Udayangani Jayawickrama ${ }^{1}$, Chrishantha Abeysena ${ }^{2}$
}

(Index words: endometrial cancer, awareness, care seeking pattern, postmenopausal)

\begin{abstract}
Introduction Variations in endometrial carcinoma awareness among postmenopausal women may explain the variations in care seeking pattern for symptoms associated with endometrial carcinoma.
\end{abstract}

Objectives To describe the awareness and care seeking pattern for symptoms associated with endometrial carcinoma among postmenopausal women in the district of Colombo.

Methods A community based descriptive cross sectional study was conducted among 1168 postmenopausal women in the district of Colombo, using multistage cluster sampling technique. A pre-tested interviewer administered questionnaire was used. Descriptive statistics were used to describe the awareness and care seeking pattern.

Results Of the sample, 83.6\% (95\% Cl: 81.5-85.7, $\mathrm{n}=977)$ had heard about endometrial carcinoma. About $56 \%$ of women $(n=654)$ were aware that postmenopausal bleeding was a suggestive symptom of endometrial carcinoma. Only $24.0 \%(n=280)$ knew that never conceived was a risk factor, $20.6 \%$ and $20.9 \%$ knew that physical inactivity and obesity were risk factors respectively and $28.0 \%$ knew that hormone replacement therapy was a risk factor, for endometrial carcinoma. Of the women, $26.6 \%(n=311)$ had experienced some gynaecological symptoms similar to symptoms of endometrial carcinoma during their postmenopausal period. Majority of them had disclosed to the children $(n=155,49.8 \%)$ about the symptoms, $70.7 \%(n=220)$ had sought treatment, and the most common reason for seeking treatment was physical discomfort $(n=83$, $37.8 \%)$. A majority had gone to the government hospital $(n=75,34 \%)$ to get treatment.

Conclusions Low awareness of common symptoms, risk factors and general

Ceylon Medical Journal 2019; 64: 133-139

DOI: http://doi.org/10.4038/cmj.v64i4.8993

${ }^{1}$ Ministry of Health, Sri Lanka, ${ }^{2}$ Faculty of Medicine, Ragama, Sri Lanka.

\section{Introduction}

Endometrial carcinoma is the sixth most commonly occurring carcinoma among women worldwide. Nearly 380,000 new cases of endometrial carcinoma accounted for $2.1 \%$ of total cancer cases that were reported globally in 2018 [1]. Nearly 380,000 new cases of endometrial carcinoma accounted for $2.1 \%$ of total cancer cases that were reported globally in 2018 [1].

At the present, there are no screening tests available to detect endometrial carcinoma. However, the majority of women diagnosed with endometrial carcinoma were presented with postmenopausal bleeding, potentially allowing early diagnosis of the disease among postmenopausal women [2]. Endometrial carcinoma is a disease which could be prevented and cured in case of early diagnosis $[3,4]$. However, due to lack of knowledge about the disease, economic problems, difficulties in attaining health services, the fear of having pain, the embarrassment and the false beliefs about disregarding the privacy lead the women to delay in seeking health care services, which inevitably cause a delay in diagnosis [5]. Several studies have also indicated that low awareness of the disease, symptoms, risk factors and early detection delayed women in seeking health care across the world $[6,7,8,9,10]$.

Awareness of risk factors, symptom profile and services provided in relation to endometrial cancer are insufficient among women $[9,11,12]$. However, awareness of endometrial carcinoma among healthy women in the community has only been surveyed in a few countries [11]. Early care seeking for symptoms associated with endometrial carcinoma is directly influenced by the level of knowledge and awareness of the post-menopausal women. Early identification of the suspected cancer

Correspondence: IUJ, e-mail: <iujayawickrama@gmail.com>. Received 21 May 2019 and revised version 17 September 2019 accepted 14 December 2019.

This is an open-access article distributed under the terms of the Creative Commons Attribution License, which permits unrestricted use, distribution, and reproduction in any medium, provided the original author and source are credited. 
symptoms helps in the early diagnosis of cancer. Therefore, the assessment of their awareness of the disease, risk factors, and services provided will indirectly assess and enhance their health care seeking behaviour. The present study aims to describe the awareness and care seeking pattern for symptoms associated with endometrial carcinoma among postmenopausal women in the district of Colombo.

\section{Methods}

A community-based descriptive cross-sectional study was carried out in the district of Colombo in the Western province of Sri Lanka. Data collection was carried out from November 2017 to February 2018. Postmenopausal women who had experienced permanent cessation of menstruation for at least 12 months, currently residing in the district of Colombo for at least 6 months prior to the date of the study were taken as the study population. Women who were already diagnosed with any type of cancer and women who were not able to give rational information due to any reason such as mental retardation were excluded.

Sample size was determined based on the minimum sample requirement in order to describe the awareness and care seeking pattern for symptoms associated with endometrial carcinoma among postmenopausal women, with an expected proportion of women having awareness of endometrial carcinoma as $50 \%$, pre-determined level of precision of 0.05 and $95 \%$ confidence interval. Since the cluster sampling method was used in selecting study units, the effect of clustering was overcome by making a correction for design effect with a calculated value of 2.9, which increased the precision. Thus, the calculated minimum sample size was 1114. A further adjustment for the sample size was done by adding five percent $(5 \%)$ to account the non-response for participation. Finally, the total sample size was taken as 1200 by rounding up to divide clusters easily.

Multi-staged, cluster sampling technique was used to select a total sample of 1200 study units in the district of Colombo. The district comprises of thirteen Divisional Secretariat (DS) divisions and study units were selected from all 13 DS divisions. In the first stage, sample was selected to be probability proportional to size (PPS) of the population living in different Grama Niladhari (GN) divisions of 13 DS divisions in the district. A cluster was defined as a group of postmenopausal women in a GN division and the number of study units in a cluster was taken as 20. There were $60 \mathrm{GN}$ divisions from total of 557 GN divisions in Colombo district were selected. The secondary sampling unit was a household. The second stage of sampling was to select 20 households using systematic sampling method from each of these selected GN divisions. At the final stage, only one eligible woman was selected from one household using simple random method. This process was repeated until the 20 study units were selected in one cluster.
An interviewer administered questionnaire including variables to describe the awareness and care seeking pattern for symptoms associated with endometrial carcinoma was used.

It was developed based on the evidence taken through thorough literature review. Further refining of the questions following the initial development of the questionnaire was carried out by conducting consultative meetings with the experts from the field of Community Medicine, Gynaecology, and Oncology. The discussions were continued till there was consensus on the questionnaire by the group of experts.

The awareness of the participants on endometrial carcinoma related to probable symptoms, risk factors and general information were asked in the awareness section of the questionnaire. The information on first communication regarding a gynaecological symptom, response of the person to whom the information was given, preference of the health care facility/personnel to seek medical care for suspected symptoms, barriers to treatment seeking were asked under the care seeking pattern.

Five pre-intern medical officers were recruited as research assistants and they were trained for the data collection at the community setting. Written consent was obtained before administering the questionnaire.

The socio-demographic characteristics of the study units were described by frequency distribution. Descriptive statistics were used to describe the awareness and care seeking pattern for symptoms of EC.

Ethics clearance was obtained from the Ethics Review Committee, Faculty of Medicine, University of Kelaniya.

\section{Results}

Of the invited 1200 eligible postmenopausal women, 32 did not participate in the study, therefore the response rate was $97.3 \%$. Reason for non-participation was unavailability to gather data even after repeated visits $(n=23)$ and refusal $(n=9)$. The women among respondent and non-respondent groups were similar in respect of selected socio demographic characteristics. Sociodemographic characteristics of the study population are given in Table 1.

The majority of postmenopausal women $(n=915$, $78.3 \%, 95 \%$ CI: 75.9-80.7) were aged more than 55 years. Most of the participants were Sinhalese $(n=785,67.2 \%$, 95\% CI: 64.5-69.9). A majority were Buddhist $(\mathrm{n}=591$, 50.6\%, 95\% CI: 47.7-53.5) followed by Catholics/Christians $(\mathrm{n}=289,24.7 \%, 95 \%$ CI: 22.2-27.2). A majority of the study participants have completed G.C.E. A/L ( $\mathrm{n}=313$, $26.8 \%, 95 \%$ CI: 24.3-29.3). Also a majority of the women had never employed $(n=583,49.9 \%, 95 \%$ CI: 47.0-52.8). A higher proportion of postmenopausal women in the study population had a monthly family income of more than SLR. 30,000. Table 2 shows the awareness, whether study population had heard about endometrial carcinoma, and if so, the source of awareness. 
A majority of the study population had heard about endometrial carcinoma ( $\mathrm{n}=977,83.6 \%, 95 \%$ CI: 81.5-85.7) through the television $(n=735,75.2 \%, 95 \%$ CI: 72.5-77.9) and then from the newspapers or magazines $(n=495,50.6 \%, 95 \%$ CI: 47.5-53.7).

Table 3 shows the awareness of the study population on symptoms suggestive of endometrial carcinoma, common risk factors and general information of the disease.

Table 1. Socio-demographic characteristics of the study population

\begin{tabular}{|c|c|c|c|}
\hline \multirow[t]{2}{*}{ Characteristics } & & \multicolumn{2}{|c|}{ Postmenopausal women $(N=1,168)$} \\
\hline & & No & $\%(95 \% C I)$ \\
\hline \multirow[t]{2}{*}{ Age } & 55 years or less & 253 & $21.7(19.4-24.1)$ \\
\hline & More than 55 years & 915 & $78.3(75.9-80.7)$ \\
\hline \multirow[t]{4}{*}{ Ethnicity } & Sinhala & 785 & $67.2(64.5-69.9)$ \\
\hline & Tamil & 196 & $16.7(14.6-18.8)$ \\
\hline & Muslim & 184 & $15.8(13.7-17.9)$ \\
\hline & Burgher & 4 & $0.3(0.0-0.6)$ \\
\hline \multirow[t]{4}{*}{ Religion } & Buddhist & 591 & $50.6(47.7-53.5)$ \\
\hline & Catholic/Christian & 289 & $24.7(22.2-27.2)$ \\
\hline & Hindu & 184 & $15.8(13.7-17.9)$ \\
\hline & Islam & 104 & $8.9(7.3-10.5)$ \\
\hline \multirow[t]{8}{*}{ Level of education } & No formal education & 17 & $1.5(0.8-2.2)$ \\
\hline & Grade $1-5$ & 161 & $13.8(11.8-15.8)$ \\
\hline & Grade $6-10$ & 179 & $15.3(13.2-17.4)$ \\
\hline & Completed G.C.E O/Level ${ }^{1}$ & 306 & $26.2(23.7-28.7)$ \\
\hline & Grade $11-13$ & 43 & $3.7(2.6-4.8)$ \\
\hline & Completed G.C.E A/Level $^{2}$ & 313 & $26.8(24.3-29.3)$ \\
\hline & Technical/Vocational/Diploma & 94 & $8.0(6.4-9.6)$ \\
\hline & University/post graduate & 55 & $4.7(3.5-5.9)$ \\
\hline \multirow[t]{3}{*}{ Employment Status } & Currently employed & 230 & $19.7(17.4-21.9)$ \\
\hline & Previously employed & 355 & $30.4(27.8-33.0)$ \\
\hline & Never employed & 583 & $49.9(47.0-52.8)$ \\
\hline \multirow[t]{4}{*}{ Monthly family income (SLR) } & $\leq 10,000$ & 121 & $10.4(8.6-12.1)$ \\
\hline & $10,001-20,000$ & 260 & $22.3(19.9-24.7)$ \\
\hline & $20,001-30,000$ & 272 & $23.3(20.9-25.7)$ \\
\hline & $>30,000$ & 515 & $44.1(41.2-46.9)$ \\
\hline Total & & 1168 & 100.0 \\
\hline
\end{tabular}

${ }^{1}$ General Certificate Exam Ordinary Level , ${ }^{2}$ General Certificate Exam Advance Level

Table 2. Awareness and source of awareness of the study population on endometrial carcinoma

\begin{tabular}{lcr}
\hline Characteristic & No & $\%(95 \%$ CI $)$ \\
\hline Aware of (heard about) endometrial carcinoma $(\mathrm{n}=1168)$ & & \\
Yes & 977 & $83.6(81.5-85.7)$ \\
No & 191 & $16.4(14.3-18.5)$ \\
Source of awareness ${ }^{*}(\mathrm{n}=977)$ & & \\
From a doctor & 252 & $25.8(23.1-28.5)$ \\
From Public Health Midwife & 105 & $10.7(8.8-12.6)$ \\
From television & 735 & $75.2(72.5-77.9)$ \\
From radio & 352 & $36.0(33.0-39.0)$ \\
From a friend/relative & 259 & $26.5(23.7-29.2)$ \\
From newspaper/magazine & 495 & $50.6(47.5-53.7)$ \\
\hline
\end{tabular}

"Multiple answers 
Table 3. Awareness of the study population on symptoms suggestive of endometrial carcinoma, common risk factors and general information

\begin{tabular}{|c|c|c|}
\hline Characteristic & No & $\%(95 \% C I)$ \\
\hline \multicolumn{3}{|c|}{ Symptoms suggestive of endometrial carcinoma* $(n=1168)$} \\
\hline Postmenopausal bleeding & 654 & $55.9(53.0-58.7)$ \\
\hline Post coital bleeding & 385 & $32.9(30.2-35.6)$ \\
\hline Offensive discharge & 310 & $26.5(24.0-29.0)$ \\
\hline Pain after sexual intercourse & 295 & $25.2(22.7-27.7)$ \\
\hline Lower abdominal pain & 376 & $32.2(29.5-34.9)$ \\
\hline \multicolumn{3}{|l|}{ General information $(n=1168)$} \\
\hline \multicolumn{3}{|l|}{$\mathrm{EC}$ is a common cancer } \\
\hline Yes & 563 & $48.2(45.3-51.1)$ \\
\hline No & 605 & $51.8(48.9-54.7)$ \\
\hline \multicolumn{3}{|l|}{$\mathrm{EC}$ is not curable } \\
\hline Yes & 309 & $26.4(23.9-28.9)$ \\
\hline No & 859 & $73.6(71.1-76.1)$ \\
\hline \multicolumn{3}{|c|}{$\mathrm{EC}$ is curable only if detected early } \\
\hline Yes & 443 & $37.9(35.1-40.7)$ \\
\hline No & 725 & $62.1(59.3-64.9)$ \\
\hline \multicolumn{3}{|c|}{ Common age of EC is after menopause } \\
\hline Yes & 360 & $30.8(28.1-33.4)$ \\
\hline No & 808 & $69.2(66.5-71.8)$ \\
\hline \multicolumn{3}{|l|}{ EC can be detected early } \\
\hline Yes & 598 & $51.2(48.3-54.1$ \\
\hline No & 570 & $48.8(45.9-51.7)$ \\
\hline \multicolumn{3}{|l|}{ Common risk factors $(\mathrm{n}=1168)$} \\
\hline Conception & 280 & $24.0(21.5-26.4)$ \\
\hline Never conceived & 888 & $76.0(73.5-78.4)$ \\
\hline \multicolumn{3}{|l|}{ Ever conceived } \\
\hline \multicolumn{3}{|c|}{ Hormone Replacement Therapy (HRT) } \\
\hline Yes & 327 & $28.0(25.4-30.6)$ \\
\hline No & 841 & $72.0(69.4-74.6)$ \\
\hline \multicolumn{3}{|l|}{ Early Menarche } \\
\hline Yes & 176 & $15.1(13.0-17.1)$ \\
\hline No & 992 & $84.9(82.8-86.9)$ \\
\hline \multicolumn{3}{|l|}{ Late Menopause } \\
\hline Yes & 188 & $16.1(13.9-18.2)$ \\
\hline No & 980 & $83.9(81.8-86.0)$ \\
\hline \multicolumn{3}{|l|}{ Physical Inactivity } \\
\hline Yes & 241 & $20.6(18.3-22.9)$ \\
\hline No & 927 & $79.4(77.1-81.7)$ \\
\hline \multicolumn{3}{|l|}{ Obesity } \\
\hline Yes & 244 & $20.9(18.6-23.2)$ \\
\hline No & 924 & $79.1(76.8-81.4)$ \\
\hline \multicolumn{3}{|l|}{ Diabetes Mellitus } \\
\hline Yes & 274 & $23.5(21.1-25.9)$ \\
\hline No & 894 & $76.5(74.1-78.9)$ \\
\hline \multicolumn{3}{|l|}{ Hypertension } \\
\hline Yes & 277 & $23.7(21.3-26.1)$ \\
\hline No & 891 & $76.3(73.9-78.7)$ \\
\hline
\end{tabular}

${ }^{*}$ Multiple answers 
More than half of the study population ( $\mathrm{n}=654,55.9 \%$, 95\% CI: 53.0-58.7) had the awareness that postmenopausal bleeding was suggestive symptom of endometrial carcinoma. When the general information about endometrial carcinoma was considered, $48.2 \%(n=563)$ of the study population believed that endometrial carcinoma was a common cancer. When the common risk factors were considered, only $24.0 \%(\mathrm{n}=280)$ knew never conceived was a risk factor and $28.0 \%$ knew HRT was a risk factor for endometrial carcinoma.

Table 4 depicts the experience of any gynaecological symptom during postmenopausal period, information on first communication regarding the gynaecological symptom and response of the person to whom the information was given. In the study population, $26.6 \%$ $(n=311)$ had experienced any gynaecological symptom similar to symptoms of endometrial carcinoma during their postmenopausal period. Among women who experienced gynaecological symptoms, a majority of them had disclosed to the children ( $\mathrm{n}=155,49.9 \%, 95 \%$ CI: 44.3-55.5) about the symptoms and the most common advice received by the women was to meet a doctor or Specialist Gynaecologist \& Obstetrician ( $\mathrm{n}=124,41.7 \%$, 95\% CI: 36.1-47.3).

Preferences of the health care facility/personnel to seek medical care for suspected symptoms and barriers to treatment seeking are given in Table 5. Of the women who experienced gynaecological symptoms, 70.7\% $(n=220)$ had sought treatment, and the most common reason for treatment seeking was physical discomfort $(\mathrm{n}=83,37.8 \%, 95 \%$ CI: 31.4-44.2). A majority had gone to the government hospital ( $n=75,34 \%, 95 \%$ CI: 27.7-40.3) to get treatment. When the reason for selecting the first health care provider was considered, $76.8 \%(n=169)$ had selected as it was low cost. A breakdown of reasons for not seeking treatment showed, $47.2 \%(n=43)$ thought it would be self-limiting. However, of the women who had not sought treatment $(n=91,29.3 \%, 95 \%$ CI: 24.1-34.5) for their gynaecological symptoms, more than half of women $(n=51,56.0 \%, 95 \%$ CI: 50.48-61.52) were aware that postmenopausal bleeding was a suggestive symptom of endometrial carcinoma.

Table 4. Experience of any gynaecological symptom during postmenopausal period, person to whom the symptom was first disclosed and their advice

\begin{tabular}{lcc}
\hline Characteristic & No & \\
\hline Experience of any gynaecological symptom $(\mathrm{n}=1168)$ & & $26.6(24.1-29.1)$ \\
Yes & 311 & $73.4(70.9-75.9)$ \\
No & 857 & \\
Person to whom the symptom was first disclosed (n=311) & & $32.1(26.9-37.3)$ \\
Husband & 100 & $49.9(44.3-55.5)$ \\
Children & 155 & $7.4(4.5-10.3)$ \\
Female relative & 23 & $6.1(3.4-8.8)$ \\
Friend & 19 & $4.5(2.2-6.8)$ \\
Didn't discuss with any one & 14 & \\
Advice given by them (n=297) & & $17.8(13.4-22.1)$ \\
Normal during postmenopausal period & & $28.6(23.5-33.7)$ \\
Recommended some home remedies & 53 & $7.7(4.7-10.7)$ \\
Meet Ayurveda physician & 85 & $3.7(1.5-5.8)$ \\
Meet PHM & 23 & $41.7(36.1-47.3)$ \\
Meet a doctor/VOG & 11 & $0.3(-0.3-0.9)$ \\
Meet faith healer & 124 & \\
& &
\end{tabular}


Table 5. Treatment seeking among women who experienced gynaecological symptoms

\begin{tabular}{|c|c|c|}
\hline Characteristic & No & $\%$ \\
\hline \multicolumn{3}{|l|}{ Seeking treatment $(\mathrm{n}=311)$} \\
\hline Treatment sought & 220 & $70.7(65.5-75.9)$ \\
\hline Treatment not sought & 91 & $29.3(24.1-34.5)$ \\
\hline \multicolumn{3}{|l|}{ Reason for treatment seeking $(n=220)$} \\
\hline Pain & 14 & $6.4(3.2-9.6)$ \\
\hline Fear of a cancer & 34 & $15.4(10.6-20.2)$ \\
\hline General weakness & 21 & $9.5(5.6-13.4)$ \\
\hline Physical discomfort & 83 & $37.8(31.4-44.2)$ \\
\hline Inability to deal with day to day activities & 68 & $30.9(24.8-37.0)$ \\
\hline \multicolumn{3}{|c|}{ Category of treatment provider visited first $(\mathrm{n}=220)$} \\
\hline General practitioner & 64 & $29.1(23.1-35.1)$ \\
\hline Government hospital & 75 & $34.0(27.7-40.3)$ \\
\hline Consultant Obstetrician and Gynaecologist & 42 & $19.1(13.9-24.3)$ \\
\hline Ayurveda physician & 12 & $5.5(2.5-8.5)$ \\
\hline Faith healer & 3 & $1.4(-0.1-2.9)$ \\
\hline Home remedies & 24 & $10.9(6.8-15.0)$ \\
\hline \multicolumn{3}{|c|}{ Reason for selecting the first health care provider $(n=220)$} \\
\hline Close by & 31 & $14.1(9.5-18.7)$ \\
\hline Low cost & 169 & $76.8(71.2-82.4)$ \\
\hline Well known for treatment & 8 & $3.6(1.1-6.1)$ \\
\hline Be in a position to discuss personal matters & 12 & $5.5(2.5-8.5)$ \\
\hline \multicolumn{3}{|l|}{ Reason for not seeking treatment $(n=91)$} \\
\hline Thought it was normal & 16 & $17.6(9.8-25.4)$ \\
\hline Thought it would be self-limiting & 43 & $47.2(36.9-57.5)$ \\
\hline Feeling shy to tell outsider & 9 & $9.9(3.8-16.0)$ \\
\hline Reluctance of undergoing vaginal examination & 12 & $13.2(6.2-20.1)$ \\
\hline High cost for treatment & 6 & $6.6(1.5-11.7)$ \\
\hline No accessible health facility nearby & 2 & $2.2(-0.8-5.2)$ \\
\hline Lack of decision making authority & 3 & $3.3(-0.4-6.9)$ \\
\hline
\end{tabular}

\section{Discussion}

The current study results showed that a majority of the women had heard about endometrial carcinoma through television and then through newspapers/ magazines. Inconsistent results were shown by Eftekhar and Yarandi, where the main source of health information was received as 'word of mouth' from a family member or friend [13]. The observed difference could be due to the differences in literacy level, socio-economic status and health care systems in the two different geographical locations.

When the awareness related to the common gynaecological symptoms of endometrial carcinoma inquired, only half of the sample knew postmenopausal bleeding was suggestive of endometrial carcinoma. A higher proportion of women were not aware of the common risk factors of endometrial carcinoma. Consistent results were shown in another study carried out in southern part of Sri Lanka concluding unsatisfactory level of knowledge on symptoms and risk factors among women aged between
30-56 years [11]. Inconsistent results were given by Bekar et al. higher proportion of women compared to the present study had awareness of the risk factors and early detection of endometrial carcinoma in that population in the city centre of Sivas, Turkey [6]. This observed difference could be attributed to the differences in socio-economic and literacy levels between the two countries. Further, voluntary participation of women in the study could have introduced volunteer bias as they are more concerned about their health and their knowledge is different from the general population concerned.

In the current study, of those women who experienced gynaecological symptoms, the majority of them had initially disclosed the symptom to their children. Gyenwali and colleagues showed inconsistent results where a female family member as the first choice to inform their symptoms [14]. This observed difference even between two countries which share similar socio-cultural background could be due to the differences in literacy level and perceived importance of health among individuals in two countries. 
In this study, a majority of the women who experienced gynaecological symptoms similar to endometrial carcinoma had gone to the government hospital to take treatment. Physical discomfort and inability to deal with day to day activities were the main reasons for those women to seek treatments. Treatment provider had been decided mainly based on the cost and the distance. This study further revealed, the most common reason for not seeking medical care for their symptoms was believing the symptoms to be self-limiting. Consistent results were given by Gyenwali et al [14], where the majority of women in their sample had also selected the government hospitals as the first choice to visit when facing similar health problems. Inconsistent results were shown when analysing the reasons for not taking treatments $[7,12]$. They revealed embarrassment and worry about the violation of privacy in gynaecological examinations were the main reasons discouraged them seeking treatments. Variations in socio-cultural backgrounds, inclusion of women at different age groups and differences in health care systems would have caused the above observed differences in findings compared to current study.

\section{Conclusions}

The majority of women had heard about endometrial carcinoma through television. However, a lower proportion of women were aware of the common risk factors of developing endometrial carcinoma. Of the women who experienced gynaecological symptoms during postmenopausal period, a majority had sought treatment and the government hospital was the common choice of selection due to the low cost borne. The reasons for not seeking care for the symptoms experienced revealed, the hope of selflimiting the symptom precluded them seeking treatment in majority. It is recommended to make the postmenopausal women aware of common symptoms of endometrial carcinoma and emphasize on early care seeking and early detection of the disease to achieve good prognosis through health education and health promotion programmes.

\section{Acknowledgements}

The authors wish to thank the project director and the staff of the Second Health Sector Development Project (SHSDP) of Ministry of Health, Nutrition and Indigenous Medicine for providing funds, Provincial and Regional Directors of Health Services and Medical Officers of Health in Colombo district, study participants and data collectors.

\section{Conflicts of Interest} interest.

The authors declare that they have no conflicts of

\section{Authors' contributions}

WIUJ was involved in the conceptualization of the research, literature search, data extraction, data analysis and drafting of the initial manuscript. CA was involved in conceptualization of the research, literature search, data analysis and editing the manuscript. All authors read the final manuscript.

\section{References}

1. Ferlay J, Colombet M, Soerjomataram I. Global and Regional Estimates of the Incidence and Mortality for 38 Cancers: GLOBOCAN 2018. Lyon: International Agency for Research on Cancer/World Health Organization. https:/ /onlinelibrary.wiley.com/doi/epdf/10.3322/caac.21492

2. Brand AH. (2007). The woman with postmenopausal bleeding. Aust Fam Physician 2007; 36(3): 116-20.

3. Stubert J, Gerber B. Current Issues in the Diagnosis and Treatment of Endometrial Carcinoma. Geburtshilfe und Frauenheilkunde 2016; 76(2): 170-5.

4. Lewin SN, Herzog TJ, Medel NIB, et al. Comparative Performance of the 2009 International Federation of Gynecology and Obstetrics' Staging System for Uterine corpus cancer. Obstet Gynecol. 2010; 116(5): 1141-9.

5. Cooper CP, Polonec L, Stewart SL. Gynaecologic cancer symptom awareness, concern and care seeking among US women: a multi-site qualitative study. Fam Pract 2013; 30(1): 96-104.

6. Bekar M, Guler H, Evcili F, Demirel G, Duran O. Determining the knowledge of women and their attitudes regarding gynecological cancer prevention. Asian Pac J Cancer Prev 2013; 14(10): 6055-9.

7. Chigbu CO, Aniebue U. Why south-eastern Nigerian women who are aware of cervical cancer screening do not go for cervical cancer screening. Int J Gynecol Cancer 2011; 21(7): 1282-6.

8. Cooper NAM, Clark TJ, Middleton L, et al. Outpatient versus inpatient uterine polyp treatment for abnormal uterine bleeding: randomised controlled non-inferiority study. BMJ 2015; 350: 23.

9. George M, Asab NA, Varughese E, et al. Risk awareness on uterine cancer among Australian women. Asian Pac J Cancer Prev 2014; 15(23): 10251-4.

10. Hvidberg L, Pedersen AF, Wulff CN, Vedsted P. Cancer awareness and socio-economic position: results from a population-based study in Denmark. BMC Cancer 2014; 14(1): 581.

11. Witharana, C, Wijesiriwardhana, P, Jayasekara, K, Kumari, $\mathrm{P}$, Rodrigo, C. Awareness of female malignancies among women and their partners in Southern Sri Lanka and implications for screening: a cross sectional study. $B M C$ Public Health 2015; 15(1): 1179.

12. Ackermann S, Renner SP, Fasching PA, Poehls U, Bender $\mathrm{HG}$, Beckmann MW. Awareness of general and personal risk factors for uterine cancer among healthy women. Eur J Cancer Prev 2005; 14(6): 519-24.

13. Eftekhar Z, Yarandi F. Knowledge and concerns about cancer in patients with primary gynecologic cancers. Asian Pac J Cancer Prev 2004; 5(2): 213-16.

14. Gyenwali D, Pariyar J, Onta SR. Factors Associated with Late Diagnosis of Cervical Cancer in Nepal. Asian Pac J Cancer Prev 2013; 14(7): 4373-7. 